www.jmscr.igmpublication.org

Impact Factor 5.84

Index Copernicus Value: 83.27

ISSN (e)-2347-176x ISSN (p) 2455-0450

crossref DOI: https://dx.doi.org/10.18535/jmscr/v5i6.152

Journal Of Medical Science And Clinical Research

\title{
Hepatitis B Vaccine Response in Selected Immunocompromised Population
}

\author{
Authors \\ Dr Nasha Kollathodi ${ }^{1}$, Dr Anitha Poduvail Moorkoth ${ }^{2}$, \\ Dr Ajithkumar Vellani Thamunni ${ }^{3}$, Dr Melemadathil Sreelatha ${ }^{4}$ \\ ${ }^{1,2}$ Dept. of Microbiology, Govt. Medical College, Kozhikode, Kerala, India \\ ${ }^{3}$ Dept. of Pediatrics, Govt. Medical College, Kozhikode, Kerala, India \\ ${ }^{4}$ Dept. of Nephrology, Govt. Medical College, Kozhikode, Kerala, India \\ Correspondence Author \\ Dr Nasha Kollathodi \\ Dept. of Microbiology, Govt. Medical College, Kozhikode, Kerala, India \\ Email: knasha@gmail.com, PH: 91-9048777887
}

\begin{abstract}
Background: Prevention of hepatitis $B$ is highly essential insusceptible population including immunocompromised individuals like patients with leukemia on chemotherapy and CKD patients on hemodialysis. Immune response is generally lower among these individuals. However, if protective antibody levels are attained, it confers protection on subsequent exposures to $H B V$.

Aim: To evaluate the immune response to hepatitis $B$ vaccine in immunocompromised.

Methods: A cross sectional study conducted on 100 patients at a tertiary care center in northern Kerala for a period of 1 year. The study population divided into category I- Children with leukemia on chemotherapy and category II-CKD patients on hemodialysis, immunized within past 10 years were tested for anti-HBs by quantitative ELISA. Those who had inadequate response were tested for HBsAg and additional doses administered.

Results: 76\%showed adequate anti-HBs levels (Category I- 70\% and category II- 82\%). 7 subjects detected to be HBsAg positive were children with leukemia not immunized routinely but at the time of chemotherapy. In category I, $87.5 \%$ response was detected in those immunized as part of routine primary immunization and $53.8 \%$ in those immunized at the time of chemotherapy $(p=0.009)$. In category II, $81.3 \%$ response seen with 0-1-2-6 regimen and 100\% with 0-1-2-12(p=0.499). On giving additional doses the remaining subjects also responded.

Conclusion: Protective immune response was achieved in all subjects after additional doses in indicated individuals. Immunization during chemotherapy was seen to be less effective in children with leukemia. This study emphasizes the importance of routine primary immunization.

Keywords: hepatitis b vaccine, anti-HBs, vaccine response.
\end{abstract}

\section{INTRODUCTION}

Hepatitis B virus infects more than 500 million people worldwide. It is a leading cause of chronic hepatitis, cirrhosis and hepatocellular carcinoma that accounts for more than 1 million deaths annually. Prevention of hepatitis B is of utmost importance in susceptible population. Hepatitis B vaccine confers long term protection against 
hepatitis B infection and about $90 \%$ of immunecompetent individuals undergo seroconversion following vaccination. The immune response is however substantially lower in immunecompromised especially leukemia patients on chemotherapy and chronic kidney disease patients on hemodialysis. Moreover these individuals have an increased risk of developing hepatitis B infection due to frequent exposure to blood and blood products in various procedures. ${ }^{1}$

In a study on hepatitis $B$ vaccine response in dialysis patients by Buti etal, only $73 \%$ response was detected $^{2}$. Only $28.6 \%$ vaccine response was noted in children with leukemia in a study at PGI Chandigarh by Ramesh et $\mathrm{al}^{3}$. To the best of our knowledge, no studies have been conducted for detection of protective anti-HBs levels in south India.

Though immune response is lower among immunocompromised individuals, those who achieve and maintain a protective antibody level $\geq 10 \mathrm{mIU} / \mathrm{ml}$ have a high level of protection from infection on subsequent exposures to HBV. A study was hence planned to determine the immune response following hepatitis $\mathrm{B}$ vaccination schedule in two categories of immunocompromised hosts, I- Children with leukemia on chemotherapy and II- CKD patients on hemodialysis.

\section{METHODS}

Cross-sectional study done at a tertiary care center at northern Kerala, during the period of April 2012 to March 2013 after getting approval from institutional research committee and ethics committee. Study population included 100 immunocompromised individuals who have completed the immunization schedule within 10 years, divided into 2 groups:

Category I: Children with leukemia on chemotherapy

Category II: Chronic kidney disease patients on hemodialysis

Those who have taken booster doses were excluded from the study.
The proforma was filled by directly interviewing the subject and in case of children parents were interviewed. Both height and weight of subjects were measured. With consent from subjects/ parents, 2-5 $\mathrm{ml}$ blood was collected by direct venipuncture and sera were separated and stored at $-20^{\circ} \mathrm{C}$ until the test was performed.

Antibody to HBsAg (Anti-HBs) was determined using quantitative ELISA- direct antibody sandwich enzyme immunoassay - Monolisa antiHBs plus 72566 from BIO-RAD was used. Assay procedure was done as per the manufacturer's instructions. For each assay, anti-HBs negative control and calibrators corresponding to 10, 100, 400 and $1000 \mathrm{mIU} / \mathrm{ml}$ of anti-HBs were used. The sero-protection was defined as presence of anti$\mathrm{HBs} \geq 10 \mathrm{mIU} / \mathrm{ml}$.

For quantitative interpretation, a graph was plotted with the OD of controls against their assigned concentrations, using a linear regression with Microsoft Excel 2010 and equation formulated.

The subjects were first tested for the anti-HBs antibody titer. Those having inadequate titer values less than $10 \mathrm{mIU} / \mathrm{ml}$ were tested for HBsAg by both card test (Hepa view HBsAgQUALPRO) and ELISA (Erbalisa - ERBA). HBsAg negative individuals were given an additional dose of Hepatitis B vaccine and tested after 1 month for anti-HBs. The individuals who showed levels less than $10 \mathrm{mIU} / \mathrm{ml}$ after the first additional/ booster dose were given another full series of immunization and response noted again.

The data were analyzed using PASW statistics18 and chi square test applied to find out the association between two variables. $P$ value $\leq 0.05$ was taken as significant.

\section{RESULTS}

A total of 100 subjects were included in the study. The study population was categorized into two groups:

Category I: Children with leukemia on chemotherapy - 50

Category II: Chronic kidney disease patients on hemodialysis -50 
In category I, $32(64 \%)$ were males and $18(36 \%)$ females. Twenty four $(48 \%)$ children were immunized as part of routine primary immunization with 6-10-14 weeks regimen, remaining $26(52 \%)$ were given double dose at the time of chemotherapy as $0-1-6$ as per the institutional policy.

Category II had 6 (12\%) subjects below 30 years and $44(88 \%)$ above 30 years age, 39 (78\%) males and $11(22 \%)$ females. All had taken vaccine in double dose - 48 (96\%) in 0-1-2-6 schedule and 2 $(4 \%)$ in $0-1-2-12$ schedule. (Table 1 )

Of the 100 immunocompromised subjects tested $76(76 \%)$ had adequate anti-HBs levels. 24 (24\%) had titer below $10 \mathrm{mIu} / \mathrm{ml}$ - 15 under category I and 9 under category II. Category I had $70 \%$ response with 22 (44\%) showing anti-HBs levels $>1000 \mathrm{mIU} / \mathrm{ml}$. Category II had $82 \%$ response with $4(8 \%)$ with $>1000 \mathrm{mIU} / \mathrm{ml}$ (Figure 1 ).

In category I, $87.5 \%$ response was detected in those immunized as part of routine primary immunization and $53.8 \%$ in those immunized at the time of chemotherapy $(\mathrm{p}=0.009)$ (Figure 2).
Males showed $62.5 \%$ response and females $83.3 \%$ $(\mathrm{p}=0.123)$.No statistically significant association was found between leukocyte count and vaccine response.

In category II, patients who had taken 0-1-2-6 schedule showed $81.3 \%$ response and those who had taken 0-1-2-12 schedule showed 100\%. (p $=0.499)$. $82.1 \%$ males and $81.8 \%$ females responded to initial course of vaccination $(\mathrm{p}=0.986)$.No association found between blood urea/ creatinine levels and antibody response in hemodialysis patients.

On follow up of 24 subjects(category I- 15, category II- 9) who had inadequate antibody titer,7 were found to be $\mathrm{HBsAg}$ positive, all of them being leukemia children who were not immunized routinely but given double dose at the time of chemotherapy. Four expired and 2 were lost to follow up. Among the remaining 11 subjects, 9 responded with a single additional dose. Two needed an additional full series of vaccination and one of them was an HCV infected CKD patient.

Table 1: Characteristics of study population

\begin{tabular}{|l|c|c|c|c|}
\hline \multirow{2}{*}{} & \multicolumn{2}{|c|}{$\begin{array}{r}\text { Category 1 } \\
\text { Patients with leukemia } \\
\text { on chemotherapy }\end{array}$} & \multicolumn{2}{c|}{$\begin{array}{r}\text { Category 2 } \\
\text { CKD patients } \\
\text { on hemodialysis }\end{array}$} \\
\hline & $\leq 30 \mathrm{yrs}$ & $>30 \mathrm{yrs}$ & $\leq 30 \mathrm{yrs}$ & $>30 \mathrm{yrs}$ \\
AGE & $50(100 \%)$ & 0 & $6(12 \%)$ & $44(88 \%)$ \\
\hline & Male & Female & Male & Female \\
SEX & $32(64 \%)$ & $18(36 \%)$ & $39(78 \%)$ & $11(22 \%)$ \\
\hline IMMUNISATION & $0-1-6 \mathrm{~m}$ & $6-10-14 \mathrm{wk}$ & $0-1-2-6 \mathrm{~m}$ & $0-1-2-12 \mathrm{~m}$ \\
REGIMEN & $26(52 \%)$ & $24(48 \%)$ & $48(96 \%)$ & $2(4 \%)$ \\
\hline
\end{tabular}

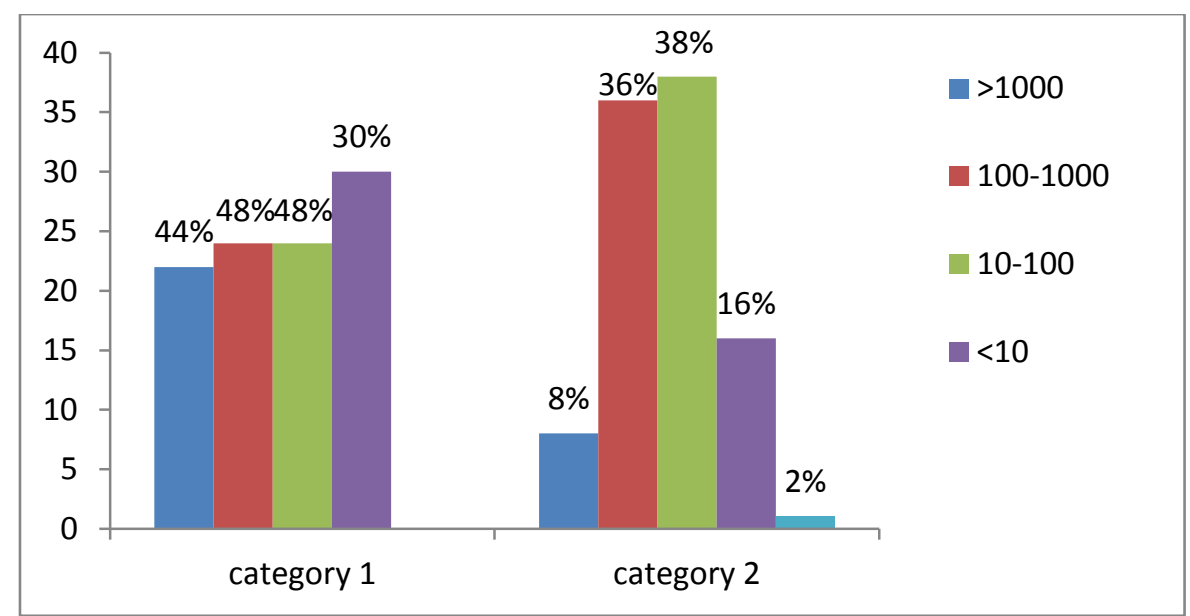

Figure1: Initial response (mIU/ml) within the two categories 


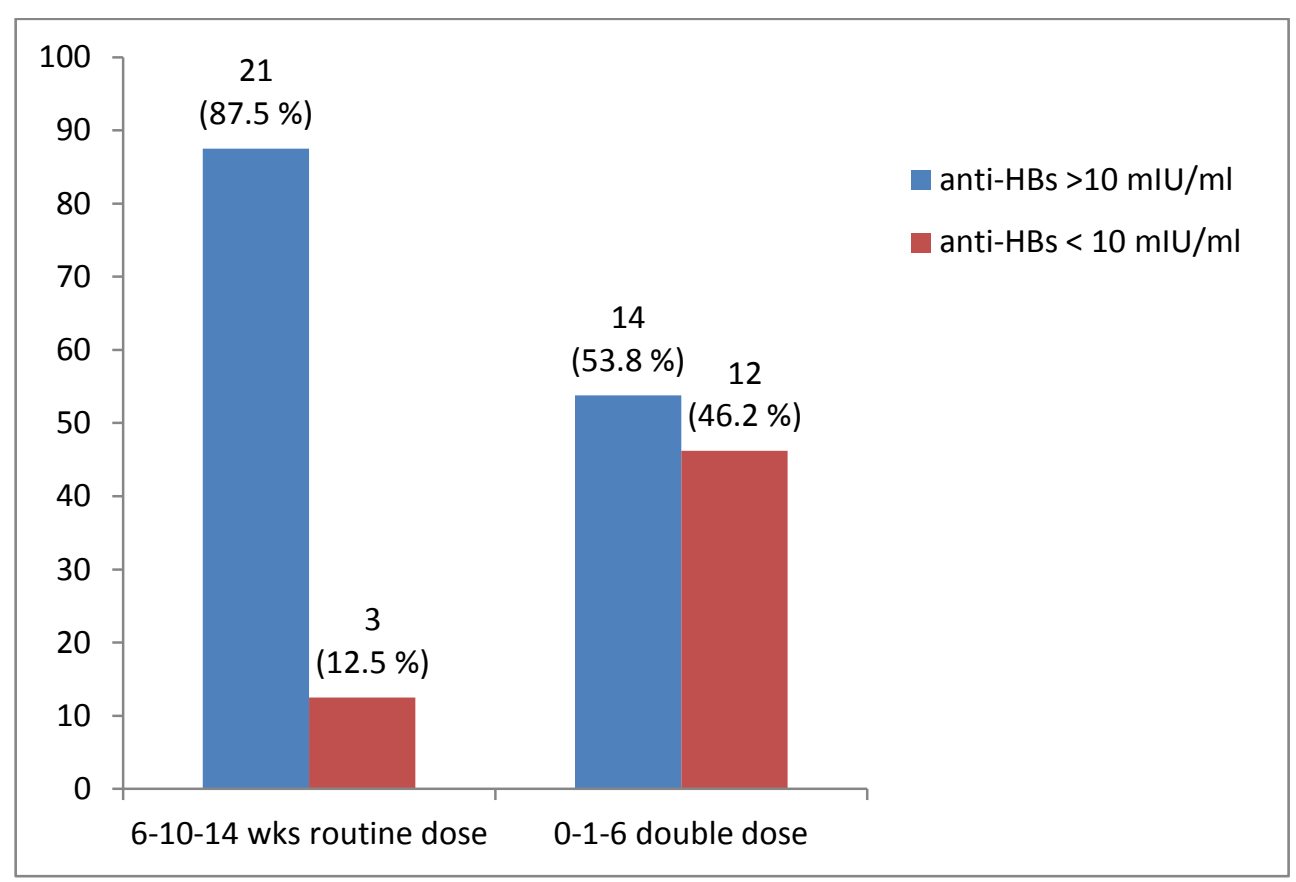

Fig 2: Response in children with leukemia

\section{DISCUSSION}

Immunocompromised individuals like leukemia patients on chemotherapy and CKD patients on hemodialysis generally respond poorly to vaccination when compared to healthy individuals. Moreover they are at increased risk of acquiring hepatitis B infection due to frequent need of blood transfusions and invasive procedures. In the present study, 100 immunocompromised subjects including 50 children with leukemia and 50 hemodialysis patients were evaluated. There was a total $76 \%$ response to initial vaccine schedule.

Of the 50 children with leukemia, 35 (70\%) responded to initial vaccine series. $21(87.5 \%)$ of 24 subjects who were vaccinated as part of primary immunization showed adequate antibody response. The remaining 26 children were not immunized routinely, they were given double dose of vaccine in 0-1-6 months schedule at the time of chemotherapy. Among them only 14 (53\%) showed an initial response $>10 \mathrm{mIU} / \mathrm{ml}$. This association between time of immunization and response is found to be statistically significant ( $p$ $=0.009$ ) and highlights the importance of primary immunization. Study by Biron Boytan et al from turkey evaluated the efficacy of primary hepatitis
B immunization in children with ALL and it emphasizes the role of primary immunization in bringing down the incidence of hepatitis $\mathrm{B}$ infection in children with leukaemia ${ }^{4}$. A similar study from north India about sero-conversion after hepatitis $\mathrm{B}$ vaccination in children receiving cancer chemotherapy by Ramesh et al, showed that only $28.6 \%$ of subjects mounted an antibody response reaching protective level after 4 double doses of recombinant $\mathrm{HB}$ vaccination indicating active immunization during chemotherapy is not very effective to protect children with leukemia from hepatitis $\mathrm{B}^{3}$.

Of the 50 hemodialysis patients studied, 41 (82\%) responded to initial vaccine schedule. All had taken double dose of vaccine. Similar to our study Mitwalli et al showed $82.3 \%$ response in hemodialysis patients by administering double the conventional dose of vaccine ${ }^{5}$. Similarly study by Ramezani et al showed $81.8 \%$ response ${ }^{6}$. Suppressed immunity in renal failure results to low hepatitis B vaccination success rates. Uremia, inadequate dialysis, use of low biocompatibility dialysis material, hyperparathyroidism, anemia, iron overload and malnutrition contribute to depressed immunity. The number of blood transfusions and the presence of a hepatitis $\mathrm{C}$ virus 
(HCV) infection or diabetes mellitus are considered additional factors for the decreased immune response ${ }^{7}$.

Of the 2 subjects who needed second full series of immunization one was $\mathrm{HCV}$ positive CKD patient. It has been reported that HCV positivity is also a risk factor for decreased immune response in hemodialysis patients ${ }^{7,8,9}$.

No statistically significant associations were found between age, sex, BMI, smoking and vaccine response.

All the patients in the study population achieved adequate antibody levels after additional vaccine doses in indicated individuals. An individual can be labelled as non-responder only if he fails to develop protective surface antibodies after completing two full series of the hepatitis B vaccine $^{10}$. In the present study no non-responders were detected. In immunocompromised patients the antibody levels should be maintained at protective level and post vaccination testing is essential in order to administer additional doses and also to determine the type of post exposure prophylaxis ${ }^{1}$. The present study indicates the need for knowing antibody response in immunocompromised patients. It also emphasizes the importance of early primary immunization.

\section{LIMITATIONS OF THE STUDY}

1. HIV infected patients were not included in the study due to ethical issues.

2. Adult patients with leukaemia were not included as they were not immunized with hepatitis B vaccine routinely in our hospital.

\section{REFERENCES}

1. Mast EE, Margolis HS, Fiore AE, Brink EW, Goldstein ST, Wang SA, et al, Center for Disease Control and Prevention: A Comprehensive Immunization Strategy to eliminate transmission of hepatitis B virus infection in the United States: recommendation of the advisory committee on immunization practices (ACIP) Part II: Immunization of adults. MMWR Recomm Rep. 55 (RR-16) : 1-23, 2006.

2. Buti M, Viladomiu L, Jardi R, et al. Longterm immunogenicity and efficacy of hepatitis B vaccine in hemodialysis patients. Am J Nephrol 1992;12(3): 144-7.

3. Ramesh M, Marwaha RK, Chawla YK, AmitaTrehan. Seroconversion After Hepatitis B Vaccination in Children Receiving Cancer Chemotherapy Indian Pediatrics 2000;37: 882-886

4. BirolBaytan, AdaletMeralGunes and UnsalGunay. Efficacy of Primary Hepatitis B Immunization in Children with Acute Lymphoblastic Leukemia. Indian Pediatrics 2008; 45:265-270

5. MitwalliA et al. Responsiveness to hepatitis B vaccine in immunocompromised patients by doubling the dose scheduling. Nephron 1996;73(3):417-20.

6. Ramezani A, Velayati AA, Eslamifar A, Banifaz M, Persistence of Hepatitis B vaccine Immunity in Hemodialysis Patients ,Therapeutic Apheresis and Dialysis Vol 12, Issue 2, pages 143-146, April2008

7. Vlassopoulos D. Recombinant hepatitis B vaccination in renal failure patients. Curr Pharm Biotechnol. 2003 Apr;4(2):141-51.

8. Wiedmann M, Liebert UG, Oesen U, et al. Decreased immunogenicity of recombinant hepatitis B vaccine in chronic hepatitis $\mathrm{C}$. Hepatology 2000;31(1):230-4.

9. Elefsiniotis IS, Vezali E, Kamposioras K, et al. Immunogenicity of recombinant hepatitis B vaccine in treatment-naive and treatment-experienced chronic hepatitis $\mathrm{C}$ patients: the effect of pegylated interferon plus ribavirin treatment. World J Gastroenterol 2006;12(27):4420-4.

10. Vaccine non responders, Hepatitis B foundation. Available at: www.hepb.org/professionals/vaccine_nonresponders.htm, accessed on 3-10-2013. 